\title{
PAD Spectrometer Based on Wide Tunable Optical Parametric Oscillator for Noninvasive Medical Diagnostics
}

\author{
D. B. Kolker ${ }^{1,2,3}$, I. V. Sherstov ${ }^{2,3}$, A. I. Karapuzikov ${ }^{2}$, A. A. Karapuzikov ${ }^{2}$, A. A. Boyko ${ }^{1,2}$, \\ M.K.Starikova ${ }^{2}$, N. Yu. Dukhovnikova ${ }^{1,2}$, V. N. Loconov ${ }^{3}$, M. Yu. Shtyrov ${ }^{2}$, \\ I. B. Miroshnichenko ${ }^{2}$, K. G. Zenov ${ }^{2}$, M. B. Miroshnichenko ${ }^{2}$ \\ ${ }^{1}$ Novosibirsk State Technical University \\ ${ }^{2}$ Special Technology LTD \\ ${ }^{3}$ OKTAVA LTD \\ Email: kolker@ngs.ru
}

Received 2013

\begin{abstract}
The gas analyzer based on optical parametric oscillators (OPO) and laser photo - acoustic spectroscopy is demonstrated. The optical parametric oscillators based on fun - out PPLN and bulk crystal $\mathrm{AgGaS}_{2}$ with a two-pass pumping are developed. Wide tunable OPO is pumped by compact nanosecond Nd: YLF laser. Pulse duration is $5-7 \mathrm{~ns}$, maximum pulse energy is $1.5 \mathrm{~mJ}$ at a frequency of $100-2000 \mathrm{~Hz}$. OPO lasing threshold is $10-16 \mathrm{~mJ} / \mathrm{cm}^{2}$ at the spectral range $2.2-$ $4 \mu \mathrm{m}$ for fun - out PPLN OPO and $12-20 \mathrm{~mJ} / \mathrm{cm}^{2}$ at the spectral range $4-7.5 \mu \mathrm{m}$ for AgGaS $\mathrm{APO}_{2}$. Absorption spectra of gaseous mixtures $\left(\mathrm{CH}_{4}, \mathrm{C}_{3} \mathrm{H}_{8}, \mathrm{C}_{2} \mathrm{H}_{6}, \mathrm{C}_{2} \mathrm{H}_{4}\right.$ and $\left.\mathrm{CO}_{2}\right)$ and human's breath were studied.
\end{abstract}

Keywords: Optical Parametric Oscillator; Nonlinear Optical Crystals; Silver Thiogallate; Fun - out PPLN; Photo Acoustic Spectroscopy; Absorption Spectrum

\section{Introduction}

At the present time registration and determination of the concentrations of various gases in the atmosphere plays an important role in biology and medical diagnostic. Analysis of the gas composition of atmosphere and human's breath is one actual directions of research.

The method of laser photo-acoustic spectroscopy (LPAS) is important for monitoring of chemical compounds in atmosphere because of its simplicity of practical realizetion, safety, cost-effectiveness and extremely high sensitivity (ppb-ppt level) [1,2].

LPAS allows taking measurements in real time. LPAS detectors do not require expensive high-reflectivity mirrors as opposed to cavity ring-down spectroscopy (CRDS) method. Capabilities of LPAS sensors generally increase with increasing laser energy as far as acoustic signal are proportional to optical power absorbed in detector. A major impact on the field of trace gas detection can be expected from new extensively tunable solid-state laser systems working in the mid - IR spectral region.

Early developed systems based on $\mathrm{CO}_{2}$-lasers combined with resonant photo-acoustic detector (PAD) a described at [3]. Our approach is determined by possibility of developing compact sealed-off waveguide $\mathrm{CO}_{2}$ lasers with specific technical parameters defined by a particular task.

In this respect the recent realization and further im- provement of optical parametric oscillators (OPOs) and quantum cascade lasers (QCL) could be an important breakthrough in the practical application of laser photoacoustic spectroscopy (LPAS) in trace gas monitoring [4].

In present time optical parametric oscillation (OPO) is one of the most effective devices to produce tunable coherent radiation in MID-IR.

\section{Laser Photo - Acoustic Spectroscopy Gas Analyzer}

\section{1. "LaserGasTest" Gas Analyzer}

LaserGasTest gas leak detector based on LPAS is presented at the Figure 1. The leak detector is destined for measuring extremely small concentration (up to $1 \mathrm{ppb}$ ) of $\mathrm{SF}_{6}$ in high-voltage gas insulated equipment [5]. $\mathrm{CO}_{2}$ laser's lines show a strong overlap with the absorption band of $\mathrm{SF}_{6}$. So, for development a $\mathrm{SF}_{6}$ gas sensor, it is enough to use $\mathrm{CO}_{2}$ laser without frequency stabilization (free-running laser). Practical testing of $\mathrm{SF}_{6}$ LaserGasTest shows that sensitivity of 1 ppb of $\mathrm{SF}_{6}$ is enough [5] for leak detection. The relative error of measurements of $\mathrm{SF}_{6}$ concentration is less than 1\% [6].

At the present time, SF6 LaserGasTest (Figure 1) gas leak detector delivering to China, Japan, Russia and 
South Korea. Nowadays SF6 LaserGasTest is being prepared for entrance to European market.

\subsection{Laser Photo - Acoustic Spectroscopy Gas Analyzer Based on Tunable Optical Parametric Oscillator}

Optical parametric oscillator (OPO) possesses broad wavelength coverage therefore we research new devices based on OPO for range extension of LPAS sensors. This technique will allow covering wide spectral range from 2.4 to $8.5 \mu \mathrm{m}$. The tuning range of nanosecond $\mathrm{OPO}$ based on PPLN crystal pumped with Nd:YLF laser is 2.4 - $3.9 \mu \mathrm{m}$ (idler wave). Expansion of the spectral range up to $8.5 \mu \mathrm{m}$ is possible by using nonlinear chalcogenide bulk crystal: $\mathrm{LiGaSe}_{2}, \mathrm{LiInSe} \mathrm{AgGaS}_{2}$, and $\mathrm{AgGaSe}_{2}$ [7-10].

The experimental OPO setup combined with photo acoustic detector was developed.

The experimental setup consists of pump laser (Qswitched Nd:YLF) and two OPO: fun - out PPLN OPO $(2.4-3.9 \mu \mathrm{m}$ ) and AGS OPO (Figure 2). The photoacoustic detector is used for registration of absorption spectra of gas samples.

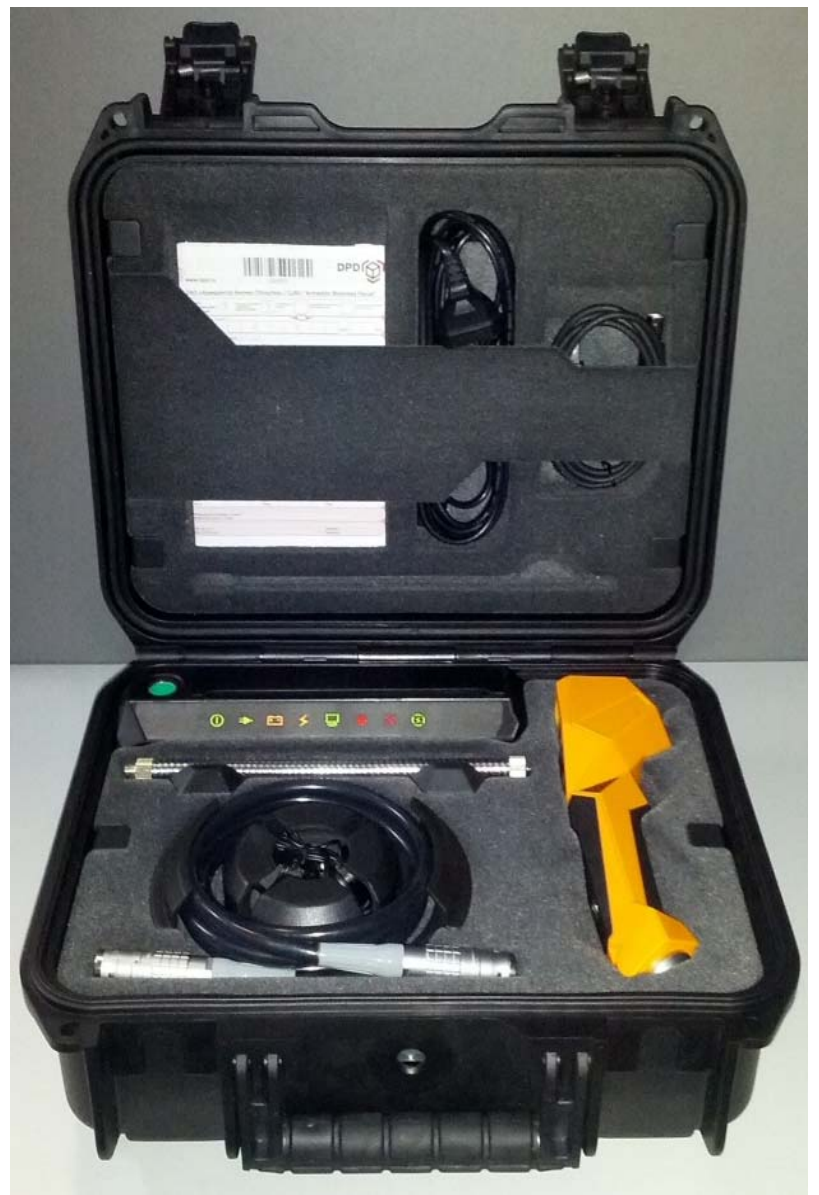

Figure 1. Photo of $\mathrm{SF}_{6}$ Laser Gas Test.

\subsubsection{Fun - Out PPLN Optical Parametric Oscillator}

The monolithic fun - out PPLN OPO cavity consist of two high-reflectivity mirrors at the signal wave (SDPOPO). The output mirror is high transparent for the pump and idler wavelengths but for the signal wavelength this mirror is high reflected. The step motor moves crystal in relation to pumping beam for the wavelength tuning.

The fun-out PPLN OPO tuning range is presented at the Figure 3.

Lasing threshold was $10-16 \mathrm{~mJ} / \mathrm{cm}^{2}$ at the spectral range $2.2-4 \mu \mathrm{m}$ for fun - out PPLN OPO.

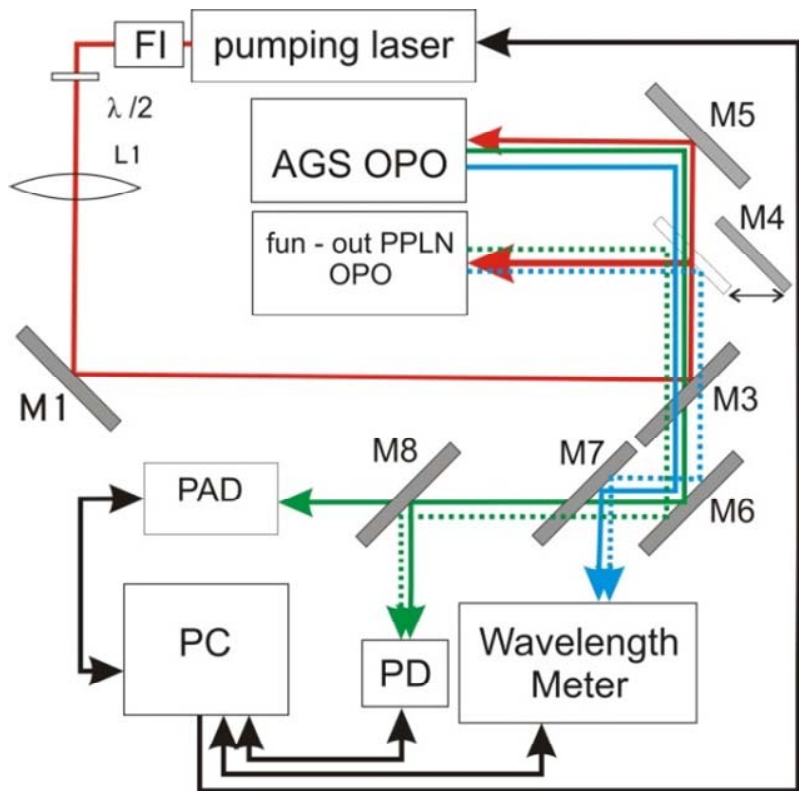

Figure 2. Scheme of experimental setup: Nd: YLF pumping laser, FI - Faraday isolator, $\lambda / 2$ - half-wave plate, M1, M5, M6 - turning mirrors, M4 - turning mirror for fun - out PPLN OPO, M3, M7 - dichroic mirrors, M8 - beamsplitter, PAD - photo - acoustic detector, PD - pyrodetector.

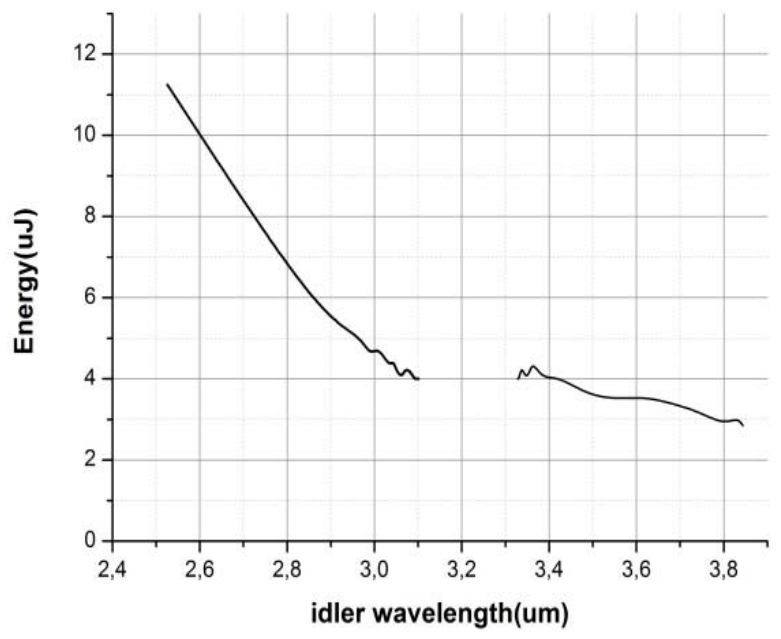

Figure 3. Fun out PPLN OPO output as a function of idler wavelength $\lambda_{\text {idler }}$ for pump energy $E_{\text {pump }} 140 \mu \mathrm{J}$. 


\subsubsection{AGS Optical Parametric Oscillator}

The advantages chalcogenide crystals are following: their relatively high thermal conductivity, large bandgap and, as a result, low two-photon absorption and low group velocities mismatching [8]. Optical parametric oscillator based on chalcogenide crystals allows covering wide spectral range from 2 to $11 \mu \mathrm{m}$.

The advantage of $\mathrm{AgGaS}_{2}$ (AGS) crystal: high effecttive nonlinear coefficient and wide optical transmission in spectral range $0.5-12.0 \mu \mathrm{m}$, makes it realistic to generate infrared parametric radiation in wide spectra range.

The monolithic AGS OPO cavity consists of two highreflectivity mirrors at the signal wave. The output mirror is transparent at the pump and idler wavelengths.

The designed monolithic block allows correcting the cavity length by changing the distance between two cylindric holders in the flanges. The step motor is using for the wavelength tuning of OPO.

The energy density of the lasing threshold is $\mathrm{J}_{\mathrm{T}}=$ $11.59 \mathrm{~mJ} / \mathrm{cm}^{2}$ at $4.4 \mu \mathrm{m}$ (idler wave). (Figures 4 and 5)

\section{Laser Photo-acoustic Detector (LPAD)}

Unlike the cavity ring-down spectroscopy (CRDS) laser photo - acoustic detectors (LPAD) do not require the use of expensive mirrors with very high reflectance. Since photo-acoustic signal is proportional to the absorbed optical power in the detector, the limiting parameters LPAS sensors generally increased with an increase in energy use of lasers.

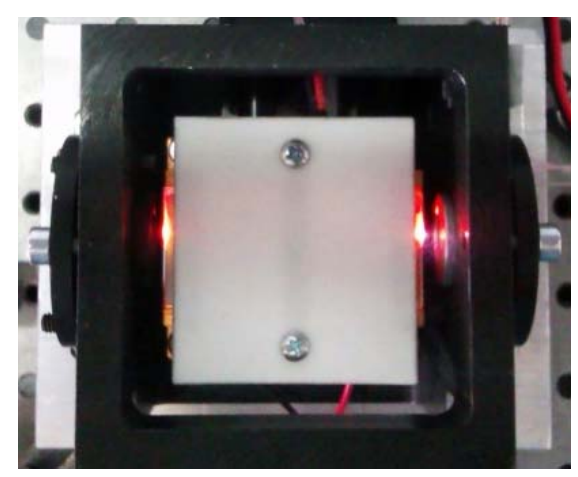

Figure 4. Fun-out PPLN OPO.

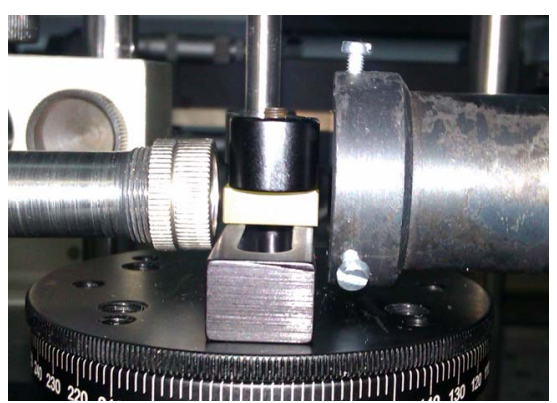

Figure 5. AGS OPO.
For excitation of photo acoustic spectra we used the nanosecond mid-IR OPO described in previous part. More often in PA devices are used sinusoidal modulated radiation and resonant cells. In the pulsed photo acoustics, the system is illuminated with a laser pulse rather than with periodic modulation. In our experiments we used the photo acoustic resonant cell.

\section{Absorption Spectra}

Absorption spectra of gaseous mixtures $\left(\mathrm{CH}_{4}, \mathrm{C}_{3} \mathrm{H}_{8}\right.$, $\mathrm{C}_{2} \mathrm{H}_{6}, \mathrm{C}_{2} \mathrm{H}_{4}$ and $\mathrm{CO}_{2}$ ) and human's breath were studied by using tandem OPO-PAD. Absorption spectra of methane and ethylene are presented on the Figures 6 and 7.

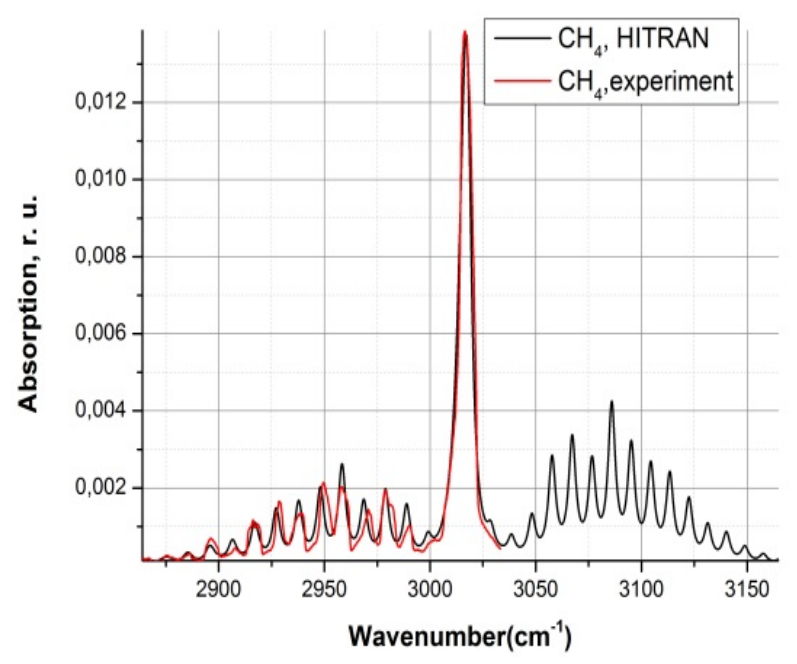

Figure 6. Absorption spectra: absorption spectrum of experimental gaseous mixture $\mathrm{CH}_{4}$ (red line) and theoretical absorption spectrum of $\mathrm{CH}_{4}$ (black line) from HITRAN.

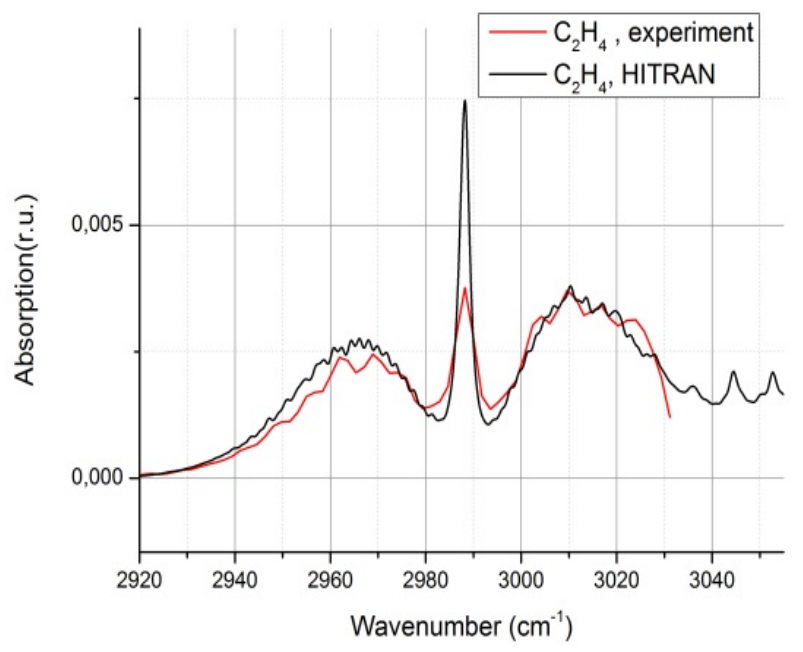

Figure 7. Absorption spectra: absorption spectrum of experimental gaseous mixture $\mathrm{C}_{2} \mathrm{H}_{4}$ (red line), absorption spectrum of $\mathrm{C}_{2} \mathrm{H}_{4}, \mathrm{HITRAN}$ (black line). 


\section{Conclusions}

Mid - IR spectrometer based on AGS OPO and fun - out PPLN OPO pumped by a $1.053 \mu \mathrm{m} \mathrm{Nd:} \mathrm{YLF} \mathrm{laser} \mathrm{was}$ demonstrated experimentally. Absorption spectra $\mathrm{CH}_{4}$, $\mathrm{C}_{3} \mathrm{H}_{8}, \mathrm{C}_{2} \mathrm{H}_{6}, \mathrm{C}_{2} \mathrm{H}_{4}, \mathrm{CO}_{2}$ and human's breath were studied by using tandem OPO-PAD. Probes of real patients (COPD, tuberculosis, asthma) are studied.

We were demonstrating new perspectives of using photo-acoustic spectroscopy for noninvasive medical diagnostics. Compact analytical systems for different applications can be developed with use of this approach.

\section{Acknowledgements}

This work was performed with support of Ministry of Education and Science of Russian Federation (contract 16.522.11.2001).

\section{REFERENCES}

[1] F. J. M. Harren, G. Cotti, J. Oomens and S. L. Hekkert, "Photoacoustic Spectroscopy in Trace Gas Monitoring," Encyclopedia of Analytical Chemistry, 2000, pp. 2203-2226.

[2] A. Miklos, P. Hess and Z. Bozoki, "Application of acoustic resonators in photoacoustic trace gas analysis and metrology," Review of Scientific Instruments, No. 72 , 2001, pp. 1937-1955

[3] Yu. N. Ponomarev, I. V. Sherstov and V. A. Vasiliev, "High-Sensitivity Laser Photoacoustic Leak Detector," Optical Engineering, Vol. 46, No. 6, 2007, p. 064302. doi: $10.1117 / 1.2748042$

[4] A. Miklos, C.-H. Lim, W.-W. Hsiang, G.-Ch. Liang, A. H. Kung, A. Schmohl and P. Hess, "Photoacoustic measurement of methane concentrations with a compact pulsed optical parametric oscillator," Applied Optics, No. 15, 2002, Vol. 41, pp. 2985-2993.

[5] I.V. Sherstov, A.I.Karapuzikov, V.A.Vasiljev, K.G. Zenov, "Research of metrological parameters of $\mathrm{SF}_{6}$ laser photo-acoustic detector", In: XV International Symposium "Atmospheric and Ocean Optics. Atmospheric Physics," Krasnoyarsk, June 22-28, 2008, p. 108.

[6] D. A. Kashtanov, V. A. Vasil'ev, A. I. Karapuzikov and I. V. Sherstov. "The stabilization emission line of waveguide $\mathrm{CO}_{2}$ laser for laser photo-acoustic detector SF6," Atmospheric and Oceanic Optics, Vol. 24, No. 6, 2011, pp. 411-424.

[7] G. Marchev, A. Tyazhev, V. Vedenyapin, D. Kolker and A. Yelisseyev. "Nd:YAG pumped nanosecond optical parametric oscillator based on $\mathrm{LiInSe}_{2}$ with tunability extending from 4.7 to $8.7 \mu \mathrm{m}$ " Optics Express, 2009, Vol. 17, No. 16, pp. 13441-13446.

[8] V. Petrov, J.-J. Zondy, O. Bidault, L. Isaenko, V. Vedenyapin, A. Yelisseyev, W. Chen, A. Tyazhev, S. Lobanov, G. Marchev and D. Kolker, Optical, thermal, electrical, damage, and phase-matching properties of lithium selenoindate //JOSA B, 2010, Vol. 27, No. 9, pp. 1902-1927.

[9] D. B. Kolker, R.V. Pustovalova, M. K. Starikova, A. I. Karapuzikov, A. A. Karapuzikov, O. M. Kuznetsov and Yu. V. Kistenev, "Optical parametric oscillator within 2.4 - $4.3 \mu \mathrm{m}$ pumped with a nanosecond Nd:YAG laser," Atmospheric and Oceanic Optics, 2012, Vol. 25, No. 1, pp. 77-81.doi:10.1134/S1024856012010071 